\title{
Resistance to airflow through bedding materials used in infancy
}

\author{
D J HATCH, P HELMS, D J MATTHEW, AND D SKINNER \\ Respiratory Function Laboratory, The Hospital for Sick Children, London, and Fios Group Limited, Hawick, \\ Roxburghshire
}

SUMMARY Various bedding materials used in infancy, including duvets (or continental quilts), were tested for airflow using the British Standards Institution tests for pillows or fabrics. Resistance was also measured when the items were placed on a dummy infant face. Measurements were made on washed and unwashed garments, which were tested both dry and wet. Results suggest that all the bedding materials tested are safe for use even in the newborn period. The duvets produced slightly lower resistance to breathing than conventional blankets and sheets. In view of the wide variety of infant bedding fabrics it seems desirable for standard airflow performance requirements to be introduced.

It is well known that a young infant can become asphyxiated when sleeping on a pillow, and for this reason the Department of Health and Social Security recommends that pillows are not used under age 12 months. The recent availability of cot quilts for infants has raised the possibility of a similar risk occurring with these. The purpose of this paper is to assess the resistance to airflow of a selection of commercially available quilts, together with coverings, both dry and wet, and to compare the results with those of other bedding materials commonly used in young infants.

\section{Materials}

Cot and pram quilts were studied as supplied to Mothercare by Fios Ltd, and Portways Ltd, filled with Imperial Chemical Industries (ICI) $\mathbf{P}_{3}$ continuous-filament polyester. The primary case fabric of the cot quilts was $100 \%$ cotton and that of the pram quilts a mixture of $74 \%$ viscose and $26 \%$ nylon. A quilt cover of $50 \%$ polyester and $50 \%$ modal mixture was also studied. Unwashed samples and samples that had been washed five times according to the manufacturer's recommendations were tested, and each sample was tested dry and wet.

\section{Methods}

British Standard air permeability test. One composite sample of unwashed cot quilt and cover was subjected to the air permeability test specified by the
British Standards Institution (BSI) for pillows. ${ }^{1}$ The layout of the apparatus is shown in Fig. 1. The apparatus consists of a rigid unperforated support for the pillow or other article to be tested, over which is mounted a metal tube, $150 \mathrm{~mm}$ long and $36 \mathrm{~mm}$ in internal diameter, with a flange at the bottom. Either the support or metal tube is allowed to move in a vertical direction to submit the article under test to a thrust of 10 Newtons. The top of the tube is connected to the inlet of a rotameter, the outlet of which is connected to the suction side of a variable speed fan. A diaphragm type valve is fitted to the inlet end of the rotameter and is used to adjust the airflow to $200 \mathrm{ml} / \mathrm{s}$. The pressure across the test article should not exceed $20 \mathrm{mmH}_{2} \mathrm{O}(0 \cdot 2$ $\mathrm{kPa}$ ).

The remaining samples were tested according to the BSI air permeability test for fabrics ${ }^{2}$ using a Shirley air-permeability tester. In this apparatus the sample is clamped between 2 rubber gaskets, and a guard ring surrounding the test specimen ensures that all the measured airflow passes through the specimen with no leakage. The test area is a circle of $5.07 \mathrm{~cm}^{2}$ Airflow was measured when a pressure differential of $20 \mathrm{mmH}_{2} \mathrm{O}(0.2 \mathrm{kPa})$ was applied. Ten measurements of airflow were made on each sample.

Resistance test on dummy infant. Resistance tests were carried out on a dummy infant which was constructed by modification of an infant resuscitation head. A small hole was drilled in each 


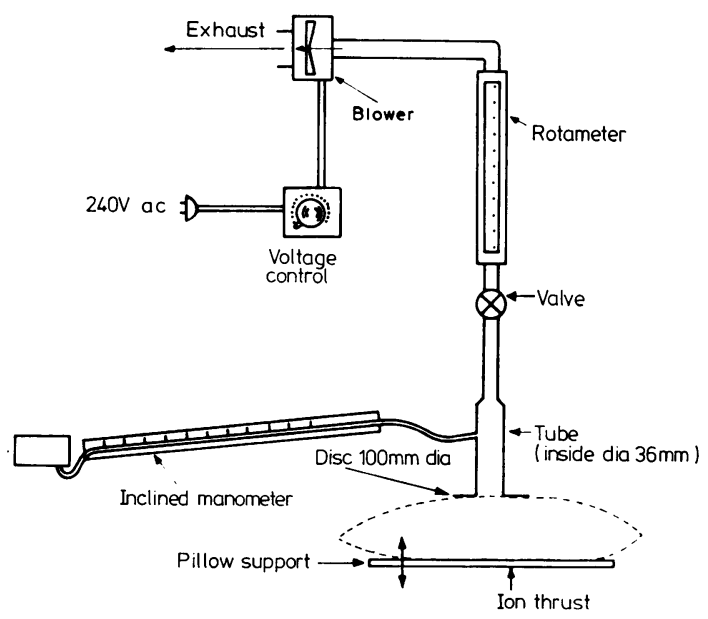

Fig. 1 Layout for air permeability test on pillows.

nostril, through which fine bore tubes were inserted and joined together within the head. The single outlet tube was then passed through the neck of the dummy and connected to a pressure transducer (SE 4-82), pneumotachograph (Fleisch ' $O$ '), and $50 \mathrm{ml}$ syringe (Fig. 2). The pressure signal from the transducer and the flow signal from the pneumotachograph were recorded on a U-V recorder (SE 6002). The pressure transducer was calibrated with a water manometer, and the pneumotachograph with gas flows from an accurate flowmeter (Rotameter Mfg. Co. Series 1100). The resistance of the system was calculated by dividing the pressure change by the change in flow occurring when the circuit was 'ventilated' with a tidal volume of $50 \mathrm{ml}$ from the syringe at a rate of 30 cycles per minute. The diameter of tubing used within the dummy head was adjusted to produce a resistance of $19 \cdot 3 \mathrm{cmH}_{2} \mathrm{O} / 1$ per second under these conditions, similar to the nasal resistance of a normal newborn baby. ${ }^{3} 4$

The materials to be tested were laid in turn loosely over the dummy head, and then were pressed

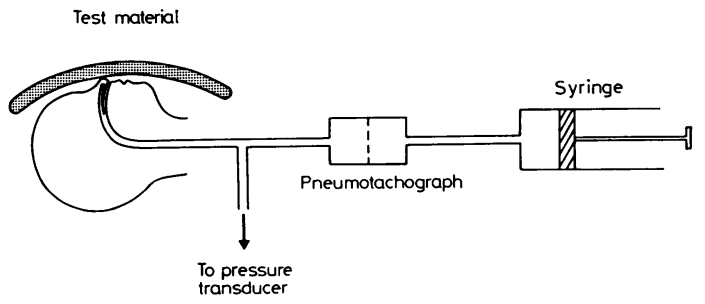

Fig. 2 Resistance test system. on to it by firm pressure around the face. In each case any increase in resistance was measured.

\section{Results}

Results are shown in Tables 1-3.

The composite sample of quilt and cover passed the BSI air permeability test for pillows with a wide margin of safety (Table 1), the mean pressure differential being less than one-quarter of the maximum permitted.

When subjected to the BSI air permeability test for other fabrics (Table 2), the highest air flows were recorded with the duvets and cellular blanket. The composite samples of duvet and cover allowed higher airflows than conventional woven blankets. Although there are no recommended minimum airflows for this test, all dry samples tested produced considerably higher flows than the $200 \mathrm{ml} / \mathrm{s}$ which might be regarded as the minimum safe airflow for pillows tested under these conditions. When wet, a range of values around this minimum airflow was obtained,

Table 1 Measurement of resistance to airflow of unwashed cot duvet and cover, tested according to British Standard BS 4578: 1970

\begin{tabular}{ll}
\hline & Pressure differential $(\mathrm{kPa})^{*}$ \\
\hline & 0.048 \\
0.048 \\
0.046 \\
0.041 \\
0.048 \\
0.038 \\
0.043 \\
0.048 \\
0.046 \\
0.048 \\
\\
Mean & 0.045 \\
\hline
\end{tabular}

*Maximum recommended"limit $=0.2 \mathrm{kPa}$.

Table 2 Measurements of airflow of unwashed bedding materials tested according to British Standard BS 5636 (1978)

Fabric Airflow ( $\mathrm{ml} / \mathrm{s}$ at a pressure gradient of $2 \mathrm{OmmH} \mathrm{mm}_{2} \mathrm{O}$ $(0.2 k P a))$

\begin{tabular}{lll} 
& Dry & Wet \\
\cline { 2 - 3 } & & \\
\hline (1) Cotton-covered quilt (duvet) & $800+$ & $180-290$ \\
(2) Polyester modal cover & $800+$ & $170-205$ \\
(3) (1) and (2) & 420 & 180 \\
(4) Cellular blanket (double thickness) & $800+$ & $800+$ \\
(5) (4) and cotton sheet (double & & \\
thickness) & 600 & 120 \\
(6) Needle punched blanket & \\
$\quad$ (double thickness) & 300 & 210 \\
(7) Woven blanket (cotton base, & & 150 \\
wool pile) & 280 & 7 \\
(8) Blanket edge binding & 65 & \\
\hline
\end{tabular}


Table 3 Resistance of various fabrics using apparatus shown in Fig. 2 ( $\mathrm{CmH}_{2} \mathrm{O} / \mathrm{l}$ per second)

\begin{tabular}{|c|c|c|c|c|c|c|}
\hline \multirow[t]{3}{*}{ Fabric } & \multicolumn{3}{|c|}{ Unwashed } & \multicolumn{3}{|c|}{ Washed } \\
\hline & \multicolumn{2}{|c|}{ Loosely applied } & \multirow{2}{*}{$\begin{array}{l}\text { Tightly held } \\
\text { Wet }\end{array}$} & \multicolumn{2}{|c|}{ Loosely applied } & \multirow{2}{*}{$\begin{array}{l}\text { Tightly held } \\
\text { Wet }\end{array}$} \\
\hline & Wet & Dry & & Wet & Dry & \\
\hline $\begin{array}{l}\text { (1) Nil } \\
\text { (2) Cotton covered quilt (duvet) } \\
\text { (3) Nylon/viscose covered quilt } \\
\text { (4) Polyester/modal cover } \\
\text { (5) (2) and (4) } \\
\text { (6) Cellular blanket and cotton sheet } \\
\text { (double thickness) }\end{array}$ & $\begin{array}{l}19.3 \\
21 \cdot 3 \\
21 \cdot 2 \\
19 \cdot 6 \\
22 \cdot 6\end{array}$ & $\begin{array}{l}19 \cdot 3 \\
22 \cdot 0 \\
21 \cdot 5 \\
21 \cdot 7 \\
23 \cdot 0\end{array}$ & $\begin{array}{l}19 \cdot 3 \\
72 \cdot 7 \\
95 \cdot 3 \\
20 \cdot 5 \\
73 \cdot 2\end{array}$ & $\begin{array}{l}19 \cdot 3 \\
19 \cdot 3 \\
22 \cdot 0 \\
21 \cdot 1 \\
20 \cdot 9\end{array}$ & $\begin{array}{l}19 \cdot 3 \\
23 \cdot 0 \\
24 \cdot 9 \\
22 \cdot 2 \\
22 \cdot 1\end{array}$ & $\begin{array}{l}19 \cdot 3 \\
25 \cdot 3 \\
39 \cdot 2 \\
25 \cdot 7 \\
40 \cdot 3\end{array}$ \\
\hline
\end{tabular}

the lowest being $170 \mathrm{ml} / \mathrm{s}$. The cellular blanket tested had very good airflow permeability when dry or wet, but other blankets were less satisfactory, the woven blanket allowing only $150 \mathrm{ml} / \mathrm{s}$ airflow when wet. The blanket edge binding was much less permeable to airflow even when dry, becoming virtually impermeable when wet.

Results of the resistance test (Table 3) show very little increase in resistance by any material laid loosely over the face of the dummy, whether wet or dry. The combination of cellular blanket and sheet produced a slightly higher resistance than the duvets. When the wet garments were held tightly around the face, resistance was about doubled.

\section{Discussion}

Sudden infant death syndrome (cot death) is the single most common cause of death between 1 month and 1 year of age.

Estimates of the total number of cot deaths in England and Wales show an incidence of 1000 a year, which is probably an underestimate. The reported incidence per 1000 live births ranges from 0.6 to $6 \cdot 5.5$

Respiratory obstruction has been suggested as a possible cause of some cases of unexplained cot death, and external obstruction by an article of bedding might conceivably contribute to this, especially in debilitated infants. The effects of pillows and mattresses in this regard have been investigated $^{6}$ and a BSI specification exists for airflow through infants' pillows. ${ }^{1}$ Furthermore the Department of Health and Social Security have stated officially that no pillow should be used for a child up to age 12 months. Little evidence is available on the effects of other types of bedding, although figures provided by the Office of Population Censuses and Surveys suggest that they may occasionally cause suffocation (Table 4) (OPCS, 1981, personal communication). Care must be taken in interpreting these figures, since the evidence for suffocation by a particular item of bedding is likely to have been circumstantial in most cases. The intro- duction of duvets for infants has raised the question of safety, particularly in the first year of life. Although it has been shown that carbon dioxide does not accumulate under duvets ${ }^{7}$ the possibility that they might cause physical obstruction across a baby's face, especially if wet, has not been investigated.

The results of this study show the performance of duvets in the BSI air permeability test for pillows to be slightly better than that of conventional blankets, with the exception of the cellular blanket. The duvets satisfied the minimum airflow requirement for pillows when dry, and approached it when wet, when their performance was slightly better than that of conventional hospital bedding. These quilts are filled with ICI's $\mathbf{P}_{3}$ continuous-filament polyester, enabling the use of a comparatively open cover fabric. It should not be assumed that the conclusions of the present study apply equally to other types of quilt.

Resistance studies carried out using the dummy

Table 4 Deaths due to suffocation in bed or cradle, 1975-77, England and Wales (data from Office of Population Censuses and Surveys, with permission)

\begin{tabular}{|c|c|c|c|c|c|c|c|c|}
\hline & \multicolumn{4}{|c|}{ Boys } & \multicolumn{4}{|c|}{ Girls } \\
\hline & \multicolumn{4}{|c|}{ Age (months) } & \multicolumn{4}{|c|}{ Age (months) } \\
\hline & $0-1$ & $1-2$ & $2-3$ & $3-4$ & $0-1$ & $1-2$ & $2-3$ & $3-4$ \\
\hline \multicolumn{9}{|l|}{ Cause of death } \\
\hline Suffocation (not specified) & 25 & 一 & 一 & 一 & 12 & 1 & 一 & 一 \\
\hline $\begin{array}{l}\text { Trapped between mattress } \\
\text { and cot/bed }\end{array}$ & 2 & 2 & - & - & 1 & - & 一 & - \\
\hline Suffocated by pillow & 6 & - & - & 一 & 2 & 一 & 1 & 一 \\
\hline Suffocated by bedding/ & & & & & & & & \\
\hline $\begin{array}{l}\text { bedclothes } \\
\text { Suffocated by mattress/ }\end{array}$ & 2 & 一 & - & - & 5 & 一 & 一 & 一 \\
\hline mattress cover & 3 & 1 & 一 & 一 & 3 & 一 & - & 一 \\
\hline Suffocated by sheet & 1 & 一 & 一 & 一 & 1 & 一 & 一 & 一 \\
\hline $\begin{array}{l}\text { Suffocated by blanket } \\
\text { Suffocated by sleeping }\end{array}$ & 1 & - & - & 一 & 一 & 一 & 一 & 一 \\
\hline bag cover & 一 & 一 & 一 & 一 & 1 & 一 & - & 一 \\
\hline $\begin{array}{l}\text { Total deaths due to } \\
\text { strangulation/suffocation } \\
\text { in bed or cradle (as } \\
\text { defined by Int. Class. } \\
\text { Dis. Cat. E. } 913.0 \text { ) }\end{array}$ & 57 & 9 & 1 & 一 & 44 & 16 & 2 & 一 \\
\hline
\end{tabular}


infant head show little increase in resistance by any material unless wet and held tightly to the face. This is a more severe test of external respiratory obstruction than a newborn baby is likely to face, and produced nothing like the 30 - to 40 -fold increase in obstruction that Emery and Thornton found when testing different types of pillow. ${ }^{6}$ Again the duvets caused slightly less resistance than other materials tested, including a combination of cellular blanket and cotton sheet commonly used in newborn nurseries throughout the country. The resistance of the washed fabrics when subjected to this test was significantly lower than that of the unwashed fabrics, being about double the normal nasal resistance of the newborn. This increase in resistance, even if it should occur in reality, should not pose a threat to the life of a normal baby.

Although a BSI test system does exist for fabrics ${ }^{2}$ no recommendations have been made for minimum airflow through bedding materials when tested. In view of the increasing use of duvets and baby nests made of a wide range of fabrics, and the suspicions recently cast on the safety of some of them ${ }^{8}$ it seems desirable that such recommendations should be introduced.

\section{References}

1 British Standards Institution. Methods of test for hardness of, and for airflow through, infants' pillows. BS 4578. 1970.

2 British Standards Institution. Method of test for the determination of the permeability of fabrics to air. BS 5636. 1978.

3 Stocks J, Godfrey S. Nasal resistance during infancy. Respir Physiol 1978; 34: 233-46.

4 Lacourt G, Polgar G. Interaction between nasal and pulmonary resistance in newborn infants. $J$ Appl Physiol 1971 ; 30: 870-3.

5 Valdes-Dapena M A. Sudden infant death syndrome: a review of the medical literature 1974-1979. Pediatrics 1980; 66: 597-614.

6 Emery J L, Thornton J A. Effects of obstruction to respiration in infants, with particular reference to mattresses, pillows, and their coverings. $\mathrm{Br}$ Med J 1968; iii: 209-13.

7 Bolton D P G, Cross K W, McKettrick A. Are babies in carry-cots at risk from $\mathrm{CO}_{2}$ accumulation? $\mathrm{Br}$ Med $\mathrm{J}$ 1972 ; iv: $80-1$

8 Anonymous. Baby's death blamed on Mothercare mattress. The Times 1981; 20 May, p. 1.

Correspondence to Dr D J Hatch, The Hospital for Sick Children, Great Ormond Street, London WC1N $3 \mathrm{JH}$.

Received 12 October 1981 